GEOGRAPHY

\section{Going all the way}

\section{Andrew Robinson follows the feet, wheels, ships and space stations that have circled the globe.}

I $n$ the depths of the cold war, the new nuclear submarine USS Triton made the first underwater circumnavigation of the globe in just 84 days. During this covert mission, the crew collected oceanographic and gravitational data, discovered an undersea peak in the mid-Atlantic Ocean and studied the response of human beings to a closed and cramped environment - information deemed useful by the burgeoning US space programme.

The pioneering 1960 mission deliberately followed most of the route of the first-ever Earth circumnavigation, by Portuguese explorer Ferdinand Magellan and his crew in 1519-22. That expedition limped home after three years, sans leader, $86 \%$ of its men and four of its five ships. Conversely, the technologically sophisticated Triton suffered no fatalities, as its commander (and bestselling novelist) Edward Beach divulged in Around the World Submerged (Holt, 1962). But on one 3,200-kilometre detour, it delivered a crewman with a kidney stone to a small rescue party sworn to secrecy.

These two feats, along with dozens more, are expertly filleted in historian Joyce Chaplin's Round About the Earth. The book is a first of its kind: a history of circumnavigations covering sea and land, air and space, and almost all forms of transport, from feet and bicycles to Concorde and orbiting space stations. Chaplin makes telling use of details from primary sources. But, as she admits, none of the technologies - whether telegraph, aeroplanes, satellites or the Internet has, despite grand initial claims, ever "saved the world" on its own.

Choice morsels abound, including the diary of a minor Venetian nobleman who survived Magellan's voyage; the journals of Captain James Cook and his plant-hunting co-traveller Joseph Banks, a future president of the Royal Society; and Charles Darwin's Beagle diaries and letters (1832-36). We also get Following the Equator (1897) by Mark Twain; the memoirs of solo sailors and fliers such as Joshua Slocum, Francis Chichester and Wiley Post; and stories of the Soviet cosmonauts and American astronauts. Even the celebrated travels of Phileas Fogg in Jules Verne's fictional Around the World in Eighty Days rate an extensive discussion.
Chaplin has clearly taken to heart the exchange she quotes from James Boswell's The Life of Samuel Johnson. Mulling over the idea of joining Cook's second circumnavigation (in 1772-75), Boswell tests it on the great lexicographer. "One is carried away with the general grand and indistinct notion of a VOYAGE ROUND THE WORLD," says Boswell. "Yes, Sir," Johnson replies, "but a man is to guard himself against taking a thing in general."

Johnson was prescient, as Chaplin reminds us. For Cook was rewarded less for his geographical discoveries (or his application of the marine chronometer to the longitude problem) than for his essay on the prevention of scurvy, published in the Royal Society's Philosophical Transactions in 1776. The British government was deeply impressed that Cook had lost only $2.6 \%$ of his crew - and not one to scurvy, which had been the greatest killer of circumnavigating

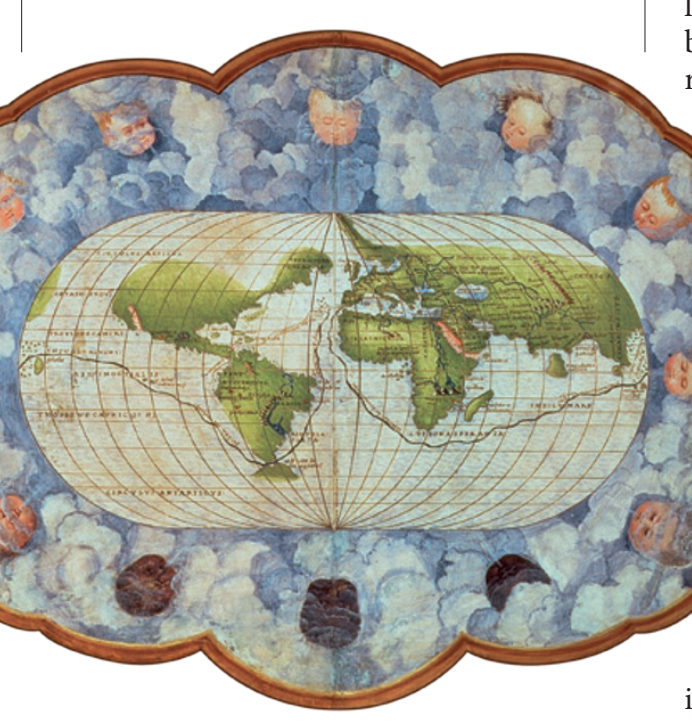

Cartographer Battista Agnese's 1545 map traces Ferdinand Magellan's expedition.

sailors since the time of Magellan.

Chaplin imposes order on her disparate material and draws meaning from it by sticking to the historical chronology of circumnavigation and dividing the half-millennium since Magellan into three major sections: "Fear", "Confidence" and "Doubt". From Magellan's violent death in the Philippines in 1521 to the notorious demise of Cook in Hawaii in 1779 , circumnavigators travelled in fear of the dangers. First among these was shipwreck, the result of poor navigational technology and stormy weather, but also starvation and disease at sea, and hostile encounters with indigenous people.

From Cook's death until the Second World War, dramatic improvements in

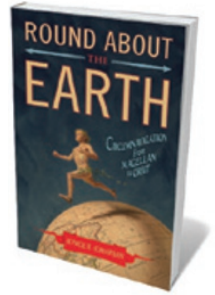

Round About the Earth: Circumnavigation from Magellan to Orbit

JOYCE E. CHAPLIN

Simon \& Schuster: 2012. 560 pp. $\$ 35$ medical treatment, transport and communications technology meant that circumnavigators had much less to fear. Perhaps most importantly, the umbrella of international imperialism endowed these explorers with planet-dominating confidence. HMS Beagle carried six guns when it set sail in 1831, whereas by 1872, HMS Challenger - a scientific expeditionary vessel exploring the deep oceans - carried a mere two. Moreover, these were intended for signalling rather than self-defence. In the mid-twentieth century, however, the old sense of danger returned, with the development of aeroplanes, rocketpropelled space capsules and the collapse of imperialism. What grew too, argues Chaplin, was doubt: the sense that Earth "is again beginning to bite back, now that the environmental costs of planetary domination have begun to haunt us".

On the whole, the book's tripartite structure works well in the first two sections, but is less convincing in the third, which strangely neglects the issue of global climatic change.

Although science and technology make their presence felt throughout the book, the emphasis is on history, politics, cultures and the personalities of the travellers - the "geodrama" of circumnavigation, as the author calls it. After all, even the scientifically distinguished James Lind (the eighteenth-century physician widely credited with introducing citrus fruits on voyages to protect against scurvy, through the first-ever clinical trial) was convinced that accommodating a sailor's yearning for land was efficacious. Lind reported without a hint of scepticism that scorbutic seamen began to revive when they were taken ashore, stripped and buried up to their necks in the earth.

Andrew Robinson is the author of The Story of Measurement and The Shape of the World: The Mapping and Discovery of the Earth.

e-mail:andrew.robinson33@virgin.net 